\title{
INFLUENZA A H1N1. REPORTE DE CASO
}

\author{
INFLUENZAA/H1N1. CASEREPORT
}

INFLUENZA AH1N1. RELATO DE CASO

\section{KIRA SÁNCHEZ PIEDRAHITA', MARGARITA BRAVO' ${ }^{1}$, XAVIER PÁEZ PESANTES' ${ }^{1}$ INÉS ARBOLEDA'}

\footnotetext{
${ }^{1}$ Hospital de niños Roberto Gilbert Elizalde; Universidad Católica de Santiago de Guayaquil; Guayaquil, Ecuador
}

RESUMEN

Objetivo: describir el comportamiento de un caso clínico de influenza AH1N1 registrado en el área de cuidados intensivos del hospital de niños "Dr. Roberto Gilbert Elizalde". Presentacion de caso: lactante mayor, previo sano, con cuadro respiratorio agudo, y severo que requiere ventilación asistida, que evoluciona a SRDA, y complicaciones de la influenza AH1N1 descritas en la literatura internacional, el cual se manejó de acuerdo a protocolos establecidos; sin embargo, su desenlace fue letal. Discusión: la influenza o gripe es una enfermedad de las vías respiratorias, causada por un virus que tiene altos niveles de contagio. Los más importantes son los virus de influenza $A$, ya que potencialmente pueden provocar epidemias y pandemias. Actualmente se considera un virus circulante a nivel mundial; sin embargo, en la actualidad aún hay casos graves que conllevan a letalidad sobre todo en pacientes de edades extremas y con comorbilidades asociadas. Conclusión: aunque en la actualidad epidemiológicamente no se considera una pandemia, el virus circulante es causante eventualmente de episodios con desenlaces fatales, como el caso antes descrito, por lo cual es importante el conocimiento de su epidemiología, el comportamiento clínico, sus complicaciones, prevención y tratamiento; junto con su manejo bajo protocolos establecidos de acuerdo a la OMS.

PALABRAS CLAVE: influenza A (H1N1), pandemias, complicaciones, prevención, tratamiento.

ABSTRACT

Objective: describe the behavior of a clinical case of influenza A/H1N1 registered in the intensive care area of the children's hospital “Dr. Roberto Gilbert Elizalde". Case presentation: older infant, previously healthy, with acute and severe respiratory symptoms that require assisted ventilation, evolving to ARDS, and complications of influenza A/H1N1 described in the international literature, which was managed according to established protocols; however, its outcome was lethal. Discussion: influenza or flu is a disease of the respiratory tract, caused by a virus that has high levels of contagion. The most important are influenza A viruses, as they can potentially cause epidemics and pandemics. Its currently considered a circulating virus worldwide; However, at present, there are still severe cases that lead to fatality, especially in patients of extreme ages and with associated comorbidities. Conclusion: Although we are not currently facing a pandemic, the circulating virus is eventually the cause of episodes with fatal outcomes, as in the case described above, which is why it is important to know its epidemiology, clinical behavior, complications, prevention, and treatment; together with its management under protocols established according to the WHO.

KEYWORDS: influenza A, pandemics, complications, prevention, treatment. 


\section{INTRODUCCIÓN}

La pandemia de gripe A (H1N1) 2009 se ha convertido en un virus estacional, que continúa circulando con otros virus desde agosto de 2010, cuando la OMS declaró el final de la pandemia. Los humanos se encuentran entre las especies que pueden infectarse con este virus de la familia orthomyxoviridae, el cual se transmite de persona a persona. ${ }^{1}$ Tiene un período de incubación de 1 a 7 días, ${ }^{1}$ es transmisible desde un día antes de los síntomas hasta 14 días. La infección se manifiesta clínicamente como una gripe común, y en los casos de mala evolución hay compromiso respiratorio y neurológico importante.

Los grupos más vulnerables son niños de 6 meses a 5 años. El tratamiento es sintomático y de soporte. Se recomienda uso de oseltamivir en pacientes con factores de riesgo o edades extremas. El lavado de manos es el método más recomendado para su prevención, además de medidas de aislamiento respiratorio y de contacto.

HISTORIA DE LA INFLUENZA AH1N1

El virus influenza AH1N1 es descendiente de la gripe española que causó una pandemia devastadora en la humanidad durante 1918-1919. Desde entonces el virus ha circulado en seres humanos durante todo el siglo XX, hasta hacer un repunte en el 2009 con la aparición de la pandemia que se extendió a nivel mundial. ${ }^{2}$ Entró a Ecuador el 15 de mayo del mismo año. Fue el 13 país en reportar casos. Casos confirmados: 2251, Muertes: 129 (pandemia 2009-2010).

\section{TRANSMISIÓN DEL VIRUS}

Diseminación persona a persona por grandes gotas $^{2,7}$ Transmisión por contacto directo físico entre infectado y susceptible, e indirecto a través de superficies contaminadas de secreciones. ${ }^{2,7}$ La supervivencia del virus es de 24 a 48 horas en superficie no porosa, 8 a 12 horas en telas tejidos y papel; y hasta 2 horas en las manos aumentando su diseminación. ${ }^{2}$

\section{CUADRO CLÍNICO}

- Fiebre mayor a $39^{\circ} \mathrm{C}$, dificultad respiratoria, taquicardia, requerimientos de $\mathrm{O} 2$ mayor a $30 \%$ en pacientes con patología de base como cardiopatía, asma severa, inmunosupresión, enfermedad pulmonar obstructiva crónica, etc. ${ }^{3}$

- En pacientes sin antecedentes, se considerarán los mismos síntomas, con requerimientos de $\mathrm{FiO} 2>40 \%{ }^{3}$
TRATAMIENTO

La nueva cepa de este virus es sensible a los inhibidores de la neuraminidasa: oseltamivir y zanamivir, no a los antivirales antiguos. ${ }^{5,7}$

\section{TABLA 1. TRATAMIENTO CON ANTIVIRALES}

\begin{tabular}{|c|c|c|c|}
\hline \multicolumn{2}{|c|}{ Agente, grupo } & Tratamiento (5 días) & $\begin{array}{l}\text { Quimioprofilaxis (10 } \\
\text { días) }\end{array}$ \\
\hline \multicolumn{4}{|c|}{ Oseltamivir } \\
\hline \multicolumn{2}{|l|}{ Adultos } & $\begin{array}{l}75 \text { mg cápsula dos } \\
\text { al día por } 5 \text { días }\end{array}$ & $\begin{array}{l}75 \text { mg cápsula una } \\
\text { vez al día }\end{array}$ \\
\hline \multirow{4}{*}{$\begin{array}{l}\text { Niños } \\
>12 \\
\text { meses } \\
\text { (peso) }\end{array}$} & $\begin{array}{l}15 \mathrm{Kg} .0 \\
\text { menos }\end{array}$ & $30 \mathrm{mg} \mathrm{C} / 12 \mathrm{hs}$ VO & 30 mg una vez al día \\
\hline & $15-23 \mathrm{Kg}$. & $45 \mathrm{mg} \mathrm{C} / 12 \mathrm{hs}$ VO & $30 \mathrm{mg}$ una vez al día \\
\hline & $24-40 \mathrm{Kg}$. & $60 \mathrm{mg} \mathrm{C} / 12 \mathrm{VO}$ & $60 \mathrm{mg}$ una vez al día \\
\hline & $\begin{array}{l}>40 \mathrm{Kg} . \mathrm{Y} \\
\text { Adultos }\end{array}$ & $\begin{array}{l}150 \text { mg por día } \\
\text { dividido en dos dosis }\end{array}$ & 75 mg una vez al día \\
\hline \multirow{3}{*}{$\begin{array}{l}\text { Niños }<12 \\
\text { meses }\end{array}$} & $<3$ meses & 12 mg 2 veces al día & No recomendada \\
\hline & $3-5$ meses & $20 \mathrm{mg} 2$ veces al día & $20 \mathrm{mg}$ una vez al día \\
\hline & $\begin{array}{l}6-11 \\
\text { meses }\end{array}$ & $25 \mathrm{mg} 2$ veces al día & $25 \mathrm{mg}$ una vez al día \\
\hline \multirow{2}{*}{\multicolumn{4}{|c|}{$\begin{array}{l}\text { Embarazada valorar riesgos/beneficios (Utilizar "Oseltamivir" según edad } \\
\text { y peso) }\end{array}$}} \\
\hline & & & \\
\hline \multicolumn{2}{|l|}{ Adultos } & $\begin{array}{l}\text { Dos inhalaciones de } \\
5 \mathrm{mg} \text { ( } 10 \mathrm{mg} \text { total) } \\
\text { dos veces al día }\end{array}$ & $\begin{array}{l}\text { Dos inhalaciones de } 5 \\
\text { mg ( } 10 \mathrm{mg} \text { total }) \text { una } \\
\text { vez al día. }\end{array}$ \\
\hline \multicolumn{2}{|l|}{ Niños } & $\begin{array}{l}\text { Dos inhalaciones } \\
\text { de } 5 \mathrm{mg} \text { ( } 10 \mathrm{mg} \\
\text { total) dos veces al } \\
\text { dia (edad } 7 \text { años y } \\
\text { mayores) }\end{array}$ & $\begin{array}{l}\text { Dos inhalaciones de } 5 \\
\text { mg ( } 10 \text { mg total) una } \\
\text { vez al día (Edad, } 5 \\
\text { años y mayores) }\end{array}$ \\
\hline
\end{tabular}

Fuente: Guía para el diagnóstico y tratamiento de la Influenza AH1N1. Comisión nacional de Influenza. Secretaria de estado de salud pública y asistencia social. Santo Domingo2009 (4)

Un reciente estudio en pacientes con influenza A (H3N2) demostró que la administración de oseltamivir antes del cuarto día se asoció a mayor reducción de la concentración de ARN viral. ${ }^{6}$ Los pacientes con neumonía grave deben tratarse con antivirales, antimicrobianos, nutrición temprana, ventilación si requiere. ${ }^{8}$ La duración del tratamiento antiviral se aconseja 10 días, demostrándose mayor efectividad si se administra dentro de las 48hrs del inicio de los sintomas. ${ }^{11}$

PREVENCIÓN

La educación y lavado de manos resultan eficaces. La OMS recomendó a los países como primera medida para proteger la infraestructura sanitaria, vacunar al personal que presta asistencia. ${ }^{10}$

COMPLICACIONES:

Pacientes en riesgo de padecer complicaciones:

- Portadores de padecimientos crónicos.

- Niños con inmunodepresión. ${ }^{9}$ 
Las infecciones bacterianas secundarias incrementan la morbimortalidad. Los agentes más comúnmente identificados son streptococcus pneumoniae, staphylococcus aureus, haemophilus influenza y bacilos gram-negativos. ${ }^{12}$

\section{CASO CLÍNICO}

Lactante mayor, procedente de área urbana, sin antecedentes patológicos previos y esquema de vacunación completo para la edad según el MSP, con cuadro de una semana de evolución caracterizado por tos en accesos, rubicundizante, no cianozante, no emetizante, acompañado de alza térmica no cuantificada; 3 días previos a su ingreso presenta dificultad respiratoria; fue llevada a distintas casas de salud, tratada ambulatoriamente con broncodilatador, paracetamol, y amoxicilina oral, pero no presenta mejoría, por lo que es llevada a emergencia del hospital Dr. Roberto Gilbert Elizalde.

En su valoración inicial luce pálida, con signos de deshidratación leve y manifestaciones de dificultad respiratoria caracterizada por quejido espiratorio, tiraje intercostal y subcostal, taquipnea quejumbrosa, saturando 92\% (escala Wood Downes Ferres) ${ }^{6}$ con soporte de oxígeno por cánula nasal.

A la auscultación pulmonar estertores húmedos bilaterales y sibilantes. Radiografía de tórax revela presencia de infiltrados intersticiales en campo pulmonar izquierdo. Infiltrados de regiones parahiliares bilaterales y en lóbulo inferior derecho. Gasometría arterial con acidosis respiratoria. Se lo aborda como insuficiencia respiratoria aguda secundaria a neumonía. Se trata con cristaloides, beta 2 inhalado, corticoide endovenoso, oxigeno por mascara facial. A las 2 horas de su ingreso se decide intubación por incremento en puntuación escala Wood Downes Ferres a 8.

Pasa a UCIP, donde se maneja sedoanalgesia y relajación, ventilación mecánica, con parámetros inicialmente de protección pulmonar, cobertura antibiótica para gérmenes atípicos y de la comunidad según grupo etario.

Sin embargo, en la primera semana de hospitalización, la evolución clínica respiratoria no es satisfactoria, presentándose en un marco de acidosis respiratoria e hipoxemia, con requerimiento de parámetros altos en el respirador, (Figura 1).

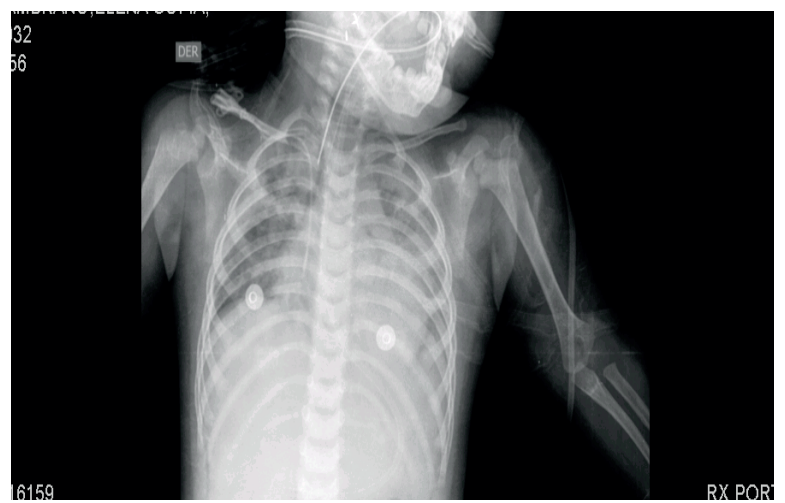

Figura 1. Radiografía tórax portátil Fuente: hospital "Dr. Roberto Gilbert Elizalde"

Se aisla virus influenza Ah1n1 por lo que se inicia oseltamivir 10 días. Al octavo día de estancia hospitalaria con caída de PAFI a 91,3 e Índice de oxigenación de 15 , se asiste con ventilación de alta frecuencia, con persistencia de hipoxemia y datos clínicos de hipertensión pulmonar, se agregó óxido nítrico. Complicaciones: neumotórax izquierdo, que ameritó drenaje, hipoxemia refractaria, evolución clínica desfavorable; paciente fallece a los 21 días de hospitalización, (Figura 2).

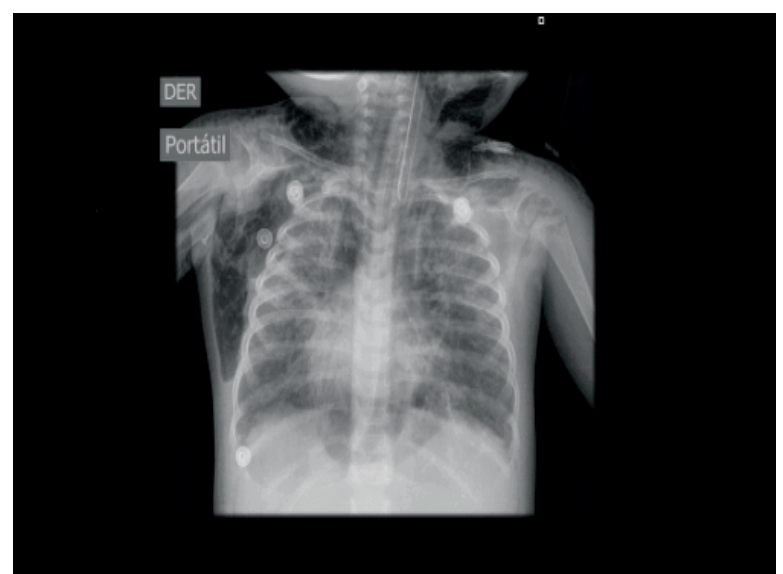

Figura 2. Radiografía tórax portátil

Fuente: Hospital "Dr. Roberto Gilbert Elizalde"

\section{DISCUSIÓN}

La gripe A (H1N1) su agente etiológico es considerado un virus circulante en nuestro medio y a nivel mundial, es causada por una variante del virus de la Influenza A que ha sufrido cambios antigénicos en la hemaglutinina y la neuraminidasa a lo largo del tiempo. Esto hace que la población sea altamente vulnerable a la infección. Su letalidad es similar a la de la influenza estacional, pero puede incrementarse en personas con factores de riesgo. 
El espectro clínico va desde personas asintomáticas hasta las formas graves que requieren internación en UCI, con rápido deterioro hasta llegar a la insuficiencia respiratoria, como en el caso expuesto, con requerimiento de asistencia ventilatoria mecánica, que progresa hacia ventilación de alta frecuencia oscilatoria, y por hipoxemia refractaria al tratamiento, el uso de óxido nítrico es procedente; sin embargo, su desenlace fue fatal.

Los estudios publicados han mostrado que los pacientes ingresados a UCI desarrollan disfunción multiorgánica, destacando la insuficiencia respiratoria aguda hipoxémica grave como alteración fisiopatológica que obligó a proporcionar soporte ventilatorio en un porcentaje de la población afecta que osciló entre el 71,8 y el 93\%. ${ }^{13}$

Esta infección puede dar lugar a enfermedad respiratoria grave y SDRA, como lo demuestra el caso descrito. La clínica es indistinguible de cualquier infección respiratoria, de modo que su diagnóstico precoz y tratamiento antiviral oportuno, son procedimientos vitales. ${ }^{14,15}$

\section{CONCLUSIÓN}

Aunque en la actualidad no estamos ante una pandemia, el virus circulante es causante eventualmente de episodios con desenlace fatal, como el caso descrito, por lo cual es importante que el personal sanitario conozca el comportamiento clínico y tratamiento de acuerdo a protocolos establecidos por la OMS.

\section{REFERENCIAS BIBLIOGRÁFICAS}

1. Influenza. Documento tecnico. Mexico: Secretaría de Salud. Subsecretaria de prevencion y promocion de la salud., Direccion general de epidemiologia; 2014.

2. Laura Margarita González Valdés OOCJG. La influenza A (H1N1): estado actual del conocimiento. Rev Ciencias Médicas. 2009 enero-marzo; 14(1).

3. Ministerio de salud publica del Ecuador. Protocolo del manejo del paciente critico con neumonia severa aso- ciado a Influenza AH1N1. Protocolo. Organizacion panamericana de la salud; 2009.

4. Secretaría de Estado de salud publica y asistencia social (SESPAS). Guia para el diagnostico y tratamiento de la Influenza AH1N1. SantoDomingo:, Comision nacional de influenza; 2009.

5. Comite de emergencias biologicas de la red de Hospitales e institutos. Nueva Gripe AH1N1 causada por el virus pandemico AH1N1 2009. Buenos Aires, Argentina: Universidad de Buenos Aires; 2010.

6. Alejandro Rodríguez TL,JR,yeG(EdTdGAGS. Gripe A (H1N1)v pandémica en UCI: ¿qué hemos aprendido? Arch Bronconeumol. 2010; 46(12).

7. Miguel Talledo KZa. Los virus Influenza y la nueva pandemia A/H1N1. Rev. peru. biol. 2009 Diciembre; 16(2).

8. Martha Gabriela Márquez MSCAdJVSH. Neumonía grave por virus AH1N1: revisión de la bibliografía a propósito de un caso. Actualidades. Med Int Mex. 2010 26; 5.

9. Ministerio de salud publica Republica de Cuba. Monografía sobre Influenza A (H1N1). Monografia. Cuba:; 2009.

10. Víctor Manuel Gutiérrez-Gómez MEOAAA. Influenza A (H1N1) 2009, epidemiologia de la pandemia, valoracion clinica y diagnostico. Arch Inv Mat Inf. 2009 mayo-agosto; I(2).

11. Comisión para la Contingencia de Influenza A (H1N1). Epidemia de la influenza A (H1N1) en la Argentina Experiencia del Hospital Nacional profesor Alejandro Posadas. MEDICINA (Buenos Aires). 2009; 69(4).

12. Paula Nardocci CEGS. Pneumonia grave por vírus influenza A H1N1 e pneumonia comunitária grave: diferenças na evolução. Rev Bras Ter Intensiva. 2013; 25(2).

13. A. Belenguer-Muncharaz RRVSATPCR. Utilización de la ventilación mecánica no invasiva en neumonía grave por virus H1Na. Med Intensiva. 2011; 35(8).

14. C. de Haro Lopez RFRyJVD. Neumonia y sindrome de distres respiratorio agudo producido por el virus de influenza AH1N1. Med Intensiva. 2009; 33(9).

15. Dr. Francisco Cordie Munoz DWRFLSRL. Neumonia por virus de influenza AH1N1 y su evolucion atipica en la unidad de cuidados intensivos. Acta medica del centro. 2014; 8(3). 